\title{
Formação inicial do professor de matemática: Utilização das TIC, dispositivos touchscreen dos tablets, no Estágio Supervisionado
}

\section{Mercedes Carvalho}

Professora, UFAL

mbettacs@uol.com.br

\begin{abstract}
Resumo
Este artigo é um recorte do projeto Tablets como recurso didático na formação inicial dos licenciandos em Matemática e Pedagogia, financiado pelo Conselho Nacional de Desenvolvimento Científico e Tecnológico (CNPq), no período 2013-2015. Elegeram-se as atividades desenvolvidas na disciplina de Estágio Supervisionado I, com os alunos do $5^{\circ}$ período, vespertino, do curso de Licenciatura em Matemática, no $2^{\circ}$ semestre de 2014, a fim de investigar como eles incorporaram o tablet, como recurso didático, para ensinar conceitos matemáticos. Para tanto, analisaram-se e organizaram-se, em categorias, os relatórios dos três alunos que cursaram a disciplina no semestre. As análises foram pautadas nos estudos de Bairral (2013), Shulman (1986), Carvalho (2012). A análise dos conteúdos revelou que a experiência para dois dos três estagiários foi profícua e que se torna urgente formar uma geração de professores de Matemática a partir de modelos pedagógicos atinentes à realidade dos alunos do século XXI.
\end{abstract}

Palavras-chave: Tablet. Tecnologia. Touchscreen. Plano de Aula.

\section{Formation of Future Mathematics Teachers: Use of ICT - Tablet Touchscreen Technology - in Supervised Practice}

\begin{abstract}
This article is part of the project Tablets as a teaching resource in the early formation of Mathematics and Education Studies teachers funded by the National Council for Scientific and Technological Development (Conselho Nacional de Desenvolvimento Científico e TecnológicoCNPq) between 2013 and 2015. For the making of this paper, activities carried out with fifth-term students from a Mathematics Teaching Formation course, who were taking the subject Supervised Practice I (Estágio Supervisionado I), were used as a base for analysis. The aim of the project was to investigate how they inserted the tablet as a resource while teaching mathematical concepts. To achieve that objective, we analyzed and organized, in different categories, the reports written by the three students who took the subject that term. The analyses were performed according to studies by Bairral (2013), Shulman (1986) and Carvalho (2012). Analyses of the reports showed that the experience was fruitful for two out of the three students and that it is urgent to form a new generation of Mathematics teachers according to educational patterns focused on $21^{\text {st }}$-century students' reality.
\end{abstract}

Keywords: Tablet. Technology. Touchscreen. Lesson Plan. 


\section{Introdução}

Ao iniciarem a carreira docente os egressos do curso de licenciatura são apresentados aos programas de governo como Tablets no Ensino Médio, Programa Nacional de Tecnologia Educacional (ProInfo), por meio de ações de formação continuada para conhecerem e se familiarizarem com os recursos que a tecnologia pode oferecer. As aprendizagens construídas nessas formações, geralmente, não são transformadas em ações na escola que possam favorecer o trabalho docente, isso porque, além de requisitos, por vezes inexistentes, como a infraestrutura da escola, o acesso à rede, o tempo disponibilizado e pessoal de apoio contribuírem para desestimular o professor a usar as Tecnologias da Informação e Comunicação (TIC) disponíveis no seu espaço de trabalho, há, também, o fato de que os modelos que esses professores construíram na sua formação inicial, possivelmente, são preponderantes, afinal "os alunos passam pelos cursos de formação sem modificar suas crenças anteriores sobre o ensino. E quando começam a trabalhar como professores, são principalmente essas crenças que eles reativam para solucionar seus problemas profissionais" (TARDIF, 2002, p. 261).

Neste cenário, tenho refletido sobre o trabalho matemático realizado com os futuros professores que terão como alunos jovens que nasceram em uma cultura mediatizada e digital presente no século XXI, mas que ainda estão sendo formados, na sua maioria, em modelos pedagógicos do século passado.

Com essa argumentação, foi aprovado pelo Conselho Nacional de Desenvolvimento Científico e Tecnológico $(\mathrm{CNPq})$ meu projeto intitulado Tablets como recurso didático na formação inicial dos licenciandos em Matemática e Pedagogia que objetivou utilizar os tablets nas aulas de Estágio Supervisionado I, disciplina da licenciatura em Matemática, e nas aulas de Saberes e Metodologia do Ensino da Matemática I e II, disciplinas do curso de Pedagogia, como recurso didático para o desenvolvimento do conteúdo matemático e da didática da matemática a partir dos aplicativos educacionais.

Neste artigo, selecionei as atividades desenvolvidas na disciplina de Estágio Supervisionado I, com os alunos do $5^{\circ}$ período do curso de Licenciatura em Matemática, que no Instituto de Matemática da Universidade Federal de Alagoas (UFAL), se dá no $5^{\circ}$ ano do ensino fundamental I, em uma escola da rede municipal de ensino de Maceió, a fim de investigar como esses futuros professores incorporaram o tablet, como recurso didático, para ensinar conceitos matemáticos.

\section{As tecnologias da informação e comunicação}


Atualmente a tecnologia nos possibilita a comunicação e informação em tempo real, assim como, a transposição das barreiras impostas pela distância. De acordo com Bairral (2013), refletir e discutir os processos de ensino e aprendizagem na atualidade implica pensar na cibercultura.

Em consonância com Santos (2012), entendo a cibercultura como a cultura contemporânea estruturada pelo uso das tecnologias digitais em rede nas esferas do ciberespaço e das cidades. Atualmente a cibercultura vem se caracterizando pela convergência de dispositivos e redes móveis (como os laptops, celulares inteligentes, mídias locativas, Internet) e pela emergência dos dispositivos que vêm estruturando redes sociais e educativas na interface ciberespaço e cidades. (Bairral, 2013, p.1)

Diante desse cenário, os alunos que frequentam a Educação Básica nasceram na era da cibercultura e seus professores, via de regra, foram formados em uma época em que as TIC se resumiam a algumas disciplinas que compunham a matriz curricular dos cursos de licenciatura. Nesse sentido, formar professores com habilidades e competências para utilizar as inúmeras possibilidades que as TIC oferecem é premente para que tenhamos mais recursos para buscar uma educação de qualidade.

O século XXI trouxe e traz provocações aos profissionais da educação, pois educar crianças e jovens para saber viver e conviver com os desafios da sociedade atual é complexo. Dessa forma, a lógica do ensino e da aprendizagem assume novas nuances, ou seja, é imperativo que os docentes do novo milênio se envolvam nos processos de ensino e ao mesmo tempo se coloquem na condição de aprendizes. Nessa direção, para Bruno (2013), o momento atual favorece uma educação caracterizada como híbrida potencializada pelas inúmeras possibilidades de ideias, espaços, tempos e seres plurais, os quais podem coexistir. Esse tipo de educação aguça a abertura de espaço para mediação pedagógica, entendida como "uma ação coletiva fundada por meio da partilha e da colaboração interativa entre os sujeitos imbuídos na constituição de redes de aprendizagem. (BRUNO, 2013, p.4). E quando a sala de aula é um espaço em que há possibilidade para a manifestação da mediação "os papéis de professor e aluno podem se fundir para se autoconstruírem e se auto-organizarem à luz das aprendizagens emergentes" (BRUNO, 2013, p.6).

Nesta perspectiva, o uso de tecnologia disponível (tablets, smartfhones, computador) como recurso didático, na formação inicial dos futuros professores de Matemática, poderá fomentar práticas pedagógicas em que eles se descubram como autores de seus processos (ensino e aprendizagem) elevando sua autoestima, isso porque, a partir do momento em que percebam serem capazes de fazer poderão assumir uma atitude proativa em relação aos conteúdos matemáticos e da Didática da Matemática, possibilitando-lhes "se fundir para se autoconstruírem e se autoorganizarem" (BRUNO, 2013, p.6). 
Rocha (2010), entretanto, alerta que ao falarmos da tecnologia em educação, não devemos nos limitar à tecnologia digital e eletrônica, mas sim considerar outras tecnologias "da mídia imagética ou visual, da sonora, da escrita, da gestual e simbólica em todos os sentidos” (p.65). Nessa perspectiva, o rádio, a televisão, o cinema, o jornal, a pintura, o som carecem de fazer parte da formação dos futuros professores, e os tablets e os smartfhones, pela mobilidade, oferecem ainda mais condições aos docentes de trabalharem com diversos aplicativos que contemplem diferentes mídias, em sala de aula.

\section{Estágio na formação inicial do professor de Matemática}

Atualmente, a resolução CNE/CP nº 2/2015 que normatiza as Diretrizes Curriculares Nacionais para Formação Inicial de Professores em Nível Superior e Formação Continuada para atuarem nos diferentes níveis da educação básica estabelece que na formação dos futuros docentes as matérias específicas (bacharelado) e pedagógicas (licenciatura) estejam distribuídas ao longo do curso na matriz curricular, ao contrário da formação $3+1$ que vigorou durante a vigência da Lei de Diretrizes e Bases Nacional 5.692/71. Reza no artigo 12, inciso I, alínea g, que "pesquisa e estudo dos conteúdos específicos e pedagógicos, seus fundamentos e metodologias, legislação educacional, processos de organização e gestão, trabalho docente, políticas de financiamento, avaliação e currículo". Portanto, a pesquisa tem destaque na formação dos futuros docentes e dessa forma "os estágios supervisionados mostram-se um celeiro de oportunidades para atender a formação dos futuros docentes com foco na investigação, isto porque eles estarão vivenciando o cotidiano escolar" (CARVALHO, 2012, p.37).

Ainda, a mesma autora, advoga que os cursos de Licenciatura em Matemática realizem estágio no $5^{\circ}$ ano do ensino fundamental, isso porque, mesmo que os licenciados em Matemática não atuem no $5^{\circ}$ ano eles serão

[...] docentes no $6^{\circ}$ ano do ensino fundamental em diante, os primeiros professores de matemática desses alunos, farão parte do rito de passagem dessa criança, e conhecer um pouco a dinâmica e a matemática dos anos iniciais pode favorecer o trabalho deste professor. (CARVALHO, 2012, p. 101-102)

Para o professor supervisor do estágio também é uma oportunidade de investigar os conhecimentos que os alunos estão desenvolvendo pois, de acordo com Lee Shulman (1986), na formação do professor devem ser levados em consideração os conteúdos do ensino e da aprendizagem, ou seja: Conhecimento do conteúdo das disciplinas (content knowledge), Conhecimento pedagógico do conteúdo (pedagogical content knowledge) e Conhecimento pedagógico do conteúdo (pedagogical content knowledge). Ao considerarmos que Shulman (1986), entende que o conhecimento pedagógico do conteúdo é a dimensão do conhecimento para ensinar, 
as estratégias que os professores utilizam para favorecer a aprendizagem dos seus alunos, no caso o estágio, possibilita ao supervisor discutir as dinâmicas e práticas observadas, porque, de acordo com Ponte (2005), a formação do professor de Matemática ancorada em questões da Matemática e da Didática da Matemática contribuiriam para que a formação dos professores se fossem "vistas de modo mais integrado" (p.16), sugerindo que na formação inicial do futuro professor a matriz curricular deve privilegiar tanto os conteúdos matemáticos quanto os seus procedimentos.

Dessa forma, o estágio é um espaço que favorece a ampliação dos conhecimentos por parte dos futuros docentes, sejam conhecimentos da matéria (Matemática), da didática da matéria (Didática da Matemática) ou curricular, pois importa romper com um modelo de formação de professores de Matemática que privilegiem apenas os conteúdos da matéria, mas que também busquem utilizar tecnologias como, por exemplo, o dispositivo touchscreen, para favorecer a construção de modelos pedagógicos que possam atender as demandas educacionais atuais.

\section{Os toques da investigação - Estudo exploratório com os tablets}

Para o desenvolvimento deste artigo, privilegiou-se o estudo exploratório entendido como modalidade que tem "como principal finalidade desenvolver, esclarecer e modificar conceitos e ideais, tendo em vista a formulação de problemas mais precisos ou hipótese pesquisáveis para estudos posteriores" (GIL, 2007, p.43). Assim a pesquisa exploratória objetiva investigar se determinada ideia é possível e permitir a familiarização com o fenômeno que se quer investigar, Fiorentini e Lorenzato (2007).

\section{A opção pelos dispositivos touchscreen}

$\mathrm{O}$ projeto aprovado pela agência de fomento $\mathrm{CNPq}$ financiou a aquisição de quarenta tablets, permitindo que nas aulas, tanto na Licenciatura em Matemática quanto no curso de Pedagogia, cada aluno manipulasse um desses objetos, possibilitando observar como os futuros docentes constroem seu conhecimento didático e matemático com esse recurso.

A opção pelo tablet se deu principalmente pela mobilidade, uma vez que ele permite o acesso à internet em diferentes espaços e aos vários aplicativos disponibilizados na Web (jogos, editor de texto, imagem, vídeo, softwares matemáticos, etc.). Outra razão para essa escolha foi o fato de que esses dispositivos móveis ganharam espaço privilegiado na vida das pessoas.

São celulares com touchscreen, notebooks, tablets e iPads que passam a fazer parte do cotidiano da maioria dos nossos alunos. Embora algumas interfaces não sejam novas, a presença dos diapositivos móveis - principalmente touchscreen - parece assumir um posicionamento de destaque no ambiente escolar por parte dos discentes, pelo menos, em seu uso pessoal. (BAIRRAL, ASSIS, SILVA, 2015, p.21). 


\section{O cenário do estudo}

Para este artigo, analisei os relatórios circunstanciados dos alunos que cursaram a disciplina Estágio Supervisionado I $-2^{\circ}$ semestre de 2014 , período vespertino, realizada nas salas do $5^{\circ}$ ano do ensino fundamental I, em uma escola pública municipal de Maceió (AL), próxima ao campus da UFAL. Os estagiários utilizaram os tablets, para desenvolver o conteúdo matemático com os alunos durante as sessões de regência de ensino. Vale salientar que antes de irmos ao trabalho de campo, em nossos encontros semanais, exploramos as possibilidades de trabalho matemático dos aplicativos e, principalmente, para instrumentalizá-los sobre a elaboração dos planos de aula. Para esse grupo de graduandos em Matemática esse trabalho foi inovador porque a tecnologia, como recurso didático, não faz parte do cotidiano deles e não há, na matriz curricular do curso, alguma disciplina que trate da tecnologia aplicada à educação. Nas aulas de Cálculo, Geometria, Álgebra Linear, Fundamentos da Matemática, por exemplo, eles usam a calculadora científica e, em algumas situações, os softweres "régua e compasso" e "geogebra". Portanto, discussões sobre o potencial didático dos aplicativos foi um momento de descoberta para esses futuros professores, além de também terem desenvolvido competências para análise dos aplicativos sob o ponto de vista de conceitos matemáticos e pedagógicos.

Devido à exigência de que para cursarem a disciplina Estágio Supervisionado I os alunos devem ter cumprido o total de 50\% do curso e, também, devido os pedidos de dispensa de algumas disciplinas de estágio por alunos que já exercem função docente ${ }^{1}$, no $2^{\circ}$ semestre de 2014 , cursaram a disciplina três alunos, aqui denominados E1, E2, E3. Portanto, analisei o conteúdo dos três relatórios apresentado por eles, organizando-os em categorias, conforme Bardin (2009), que emergiram do agrupamento de frases ou palavras recorrentes, analisadas à luz da literatura, sobre o uso das tecnologias no processo educacional e formação de professores.

\section{Reflexões sobre os tablets no processo de formação do professor de Matemática}

\section{Os tablets no processo de aprendizagem dos alunos do $5^{\circ}$ ano do ensino fundamental}

Os estagiários buscaram desenvolver atividades com o Sistema de Numeração Decimal e Geometria em que as crianças pudessem manipular tanto o material concreto quanto os aplicativos. Na aula em que levamos os tablets, os alunos tiveram a primeira oportunidade de manipularem os aparelhos e como era de se esperar ficaram eufóricos. Mesmo mostrando-se preocupados em cumprir o plano os estagiários deram mais tempo para as crianças manipularem os tablets. Nesse dia tínhamos vinte e três aparelhos em sala, pois o restante estava sendo utilizados em outra atividade.

\footnotetext{
${ }^{1}$ Em Alagoas, há carência de professores de Matemática nas escolas públicas.
} 
Distribuímos os tablets aos alunos e informamos os devidos cuidados que todos os alunos deveriam ter com o material, pois era um produto pertencente ao contribuinte e que deveríamos cuidar [...] Solicitamos a formação de duplas e fizemos a distribuição dos tablets, [...] mas deixamos que explorassem os tablets de forma livre, assim poderíamos observar quais aplicativos atrai melhor os alunos. (E1)

Deixamos à vontade com os tablets para que eles pudessem usar os jogos matemáticos que eles quisessem. Esse processo foi muito proveitoso para a minha formação, pois, pude detectar algumas dificuldades e habilidades bastante interessantes nos alunos. (E2).

De acordo com o conteúdo do relatório E1 depreende-se que esse futuro professor de Matemática buscou imprimir em sua atividade uma visão ampliada do exercício do magistério, da cidadania, ao lembrar que os tablets foram adquiridos com recursos vindo dos impostos pagos pelos contribuintes. Também, quando os estagiários deixaram os alunos explorarem os aplicativos tiveram a oportunidade de observá-los melhor. Assim, ao considerarmos o conhecimento curricular entendido por Shulman (1986), como sendo a matéria médica da Pedagogia, porque constitui espaço de mobilização dos professores; estes estagiários constroem seu conhecimento curricular quando discutem cidadania e ao observarem os alunos assumem o papel de pesquisador como reza na resolução CNE/CP nº 2/2015.

Um dos aplicativos que os estagiários trabalharam foi o SAMD (Subtração, Adição, Multiplicação e Divisão www.hypatiamat.com) - software que trabalha as quatro operações aritméticas e favorece o cálculo mental, com tempo para realização das operações. Ao observarem as crianças trabalhando com esse aplicativo perceberam as dificuldades delas em relação aos conteúdos matemáticos:

Durante as observações pude notar alguns alunos com dificuldades em divisão, a clássica foi divisão por zero, onde muitos alunos usavam zero como divisor, então fizemos a interversão e esclarecimento sobre esse processo de divisão por zero. (E1)

Um fato que me chamou bastante a atenção foi que, ao usarem um aplicativo que permitia aos alunos perceber a ideia da propriedade comutativa com relação a soma e a multiplicação eles não perceberem que faziam esse processo constantemente. (E2)

O conteúdo do relatório desses estagiários corrobora com as pesquisas de Carvalho (2010, 2012), em que a pesquisadora destaca a importância dos cursos de Licenciatura em Matemática discutirem os conteúdos do $5^{\circ}$ ano do ensino fundamental. Esses estagiários puderam observar as lacunas conceituais que a maioria dos alunos da escola pública carrega ao ingressar no $6^{\circ}$ ano do ensino fundamental e os professores de Matemática, erroneamente, atribuem ao pedagogo essas lacunas conceituais.

Formar o professor de Matemática é formá-lo para a educação básica e, para tanto é pertinente que ele tenha conhecimentos sobre todos os segmentos educacionais, o 
que, possivelmente, favorecerá seu trabalho pedagógico, pois ele terá uma visão ampliada do aluno, compreendendo melhor seu processo de aprendizagem, principalmente o aluno do $6^{\circ}$ ano (CARVALHO, 2012, p. 94).

\section{Recurso didático: material concreto e aplicativos}

O currículo e planos de cursos devem contemplar diferentes recursos pedagógicos: jogos, material concreto, computador, tablets, smartfhones, filme, música, arte, literatura paradidática a fim de apresentar diversidade de possibilidade de ensinar matemática. Como existe a possibilidade de que esses futuros professores venham a exercer a docência em uma escola em que não haja recursos tecnológicos e, se houver, sem estrutura adequada, porém, possivelmente, haverá material concreto, jogos. Por isso, uma das atividades planejadas pelos estagiários foi o Tangram, tanto no material concreto, quanto no virtual.

Foi muito interessante pois essa é a mesma classe em que já tínhamos trabalhado o tangram com material concreto. O mais proveitoso foi perceber que os alunos acharam melhor o tangram no tablet do que no material concreto. Apenas porque no tablet, para eles, era mais fácil fazer a rotação das figuras. Isso mostra uma certa dificuldade dos alunos em compreender algumas propriedades das figuras geométricas encontradas no tangram. (E2)

Esse estagiário ao comparar o Tangram no virtual e no concreto refletiu sobre o potencial dos diferentes recursos. Manipular a tela do tablet favoreceu as crianças, implicitamente, apropriarem-se de algumas propriedades das figuras geométricas já "que os gestos têm implicações na compreensão dos conceitos [...] a manipulação nas telas dos tablets pode possibilitar a elaboração de gestos que, passando a compor mais uma forma de comunicação nas aulas, favorecem a construção do conhecimento matemático" (BAIRRAL, ASSIS, SILVA, 2015, p. 27)

A segunda parte da atividade estava definida em formar as figuras disponíveis no aplicativo Tangram. Das observações sobre o aplicativo além de despertar o conhecimento das figuras geométricas, noções de proporção, coordenação motora o tablet permite que os alunos girem a figuras obtendo uma visão em diferentes posições de cada figura. (E1)

De acordo com esse relatório o estagiário 1 depreendeu que o tablet, como recurso didático, favorece a compreensão dos conteúdos matemáticos, isso porque, ao manipular a tela do tablet "ao contrário dos clicks feitos no mouse, a manipulação em interfaces touchscreen implica em continuidade de ação, na espacialidade e na simultaneidade de imputs na tela, na combinação de movimentos" (BAIRRAL, ASSIS, SILVA, 2015, p. 18) o que, quando bem explorado pelo professor, favorece o trabalho pedagógico.

Portanto, esses estagiários vivenciaram o potencial de um mesmo jogo a partir de dois recursos didáticos, virtual e concreto, o que, possivelmente, quando atuarem no magistério terão melhores condições de planejar suas aulas, porque durante a sua formação inicial, com esse estágio, 
houve momentos de integração entre os conteúdos matemáticos e da Didática da Matemática ensejando a atitude proativa o que possivelmente os "se fundir para se autoconstruírem e se autoorganizarem" (BRUNO, 2013, p.6).

\section{$O$ tablet no processo e formação do futuro professor de Matemática}

A análise dos relatórios também buscou investigar sobre como a utilização do tablet durante as aulas do estágio contribuiu para o processo de formação desses futuros professores de Matemática.

O fator diferencial deste estágio foi o uso dos tablets e seus aplicativos por todos os alunos dentro da sala de aula algo novo para os discentes, docentes e até nós estagiários, os aplicativos eram didáticos e atraentes para jogar, causando um potencial na participação dos alunos. [...] (E1)

É importante relatar que, durante a aula os alunos não quiseram ficar usando só o tangran. Eles também usaram o tablet e descobriram outros aplicativos relacionados com a matemática. Com isso, pude observar também que, os alunos compreendem melhor o conceito de fração mais pela figura do que pela expressão numérica [...] Desta forma, pode-se perceber que o uso da tecnologia em sala de aula motiva a curiosidade dos alunos bem mais que o livro e o quadro, porém não afirmo que os mesmo devem ser substituídos. (E2)

De acordo com os relatórios esses estagiários foram sensíveis ao movimento de sala de aula com o uso dos tablets e refletiram, principalmente, sobre o que pode ser caracterizado como indisciplina por alguns ou, como uma janela de aprendizagem, por outros. Nesse sentido, de acordo com Shulman (1986), o docente apreender do conhecimento pedagógico do conteúdo é fator preponderante para ensinar.

Algumas meninas usaram as câmeras dos tablets para fazerem fotografias o que
mostra que os jogos nem sempre conseguiram manter atenção total das alunas,
porém considero possível absorver matemática de muitas coisas e até mesmo nesse
momento poderia trabalhar a ideia de ângulos nas posições, proporção das fotos,
isso me fez enxergar que matemática esta contida em infinitas atividades. (E1)

Contudo, o conteúdo do relatório do estagiário 3 trouxe dados sobre os modelos ainda muito fortes das aulas tradicionais da licenciatura.

Durante o manuseio dos tablets foi dada algumas instruções, alguns comandos também, pois nem todos havia familiaridade com o equipamento. [...] Foi solicitado, após os devidos esclarecimentos, que os alunos explorassem alguns jogos. Somas, frações, tabuadas, multiplicações, subtrações, números naturais, inteiros, memoria. [...] Na quarta e ultima intervenção, foi levado novamente como recurso tablets, por se tratar de alunos maiores a expectativa da pesquisadora era que a interação fosse maior do que a intervenção anterior e também pelo que foi experiência com o tangram. Foram trabalhados os conteúdos/jogos, e o que se pôde perceber foi pouco interesse na proposta, [...]. O que foi proposto não despertou interesse dos alunos e a ferramenta apresentada não foi reconhecida como educativa por eles. (E3)

Ao contrário dos seus colegas E1 e E2, este estagiário não conseguiu observar questões importantes aos alunos manipularem os tablets, pois já que muitos não tinham familiaridade era de 
se esperar que as crianças quisessem manipular, dessa forma o plano de aula ficaria secundarizado. É possível depreender que para este estagiário, em especial, é importante experenciar, durante sua formação, atividades com o uso da tecnologia para que tenha a possibilidade de desenvolver o conhecimento didático do conteúdo, (SHULMAN, 1986), já que durante as aulas de regência demonstrou preocupação com o desenvolvimento do conteúdo matemático que estava planejado. Considero compreensível já que o aluno, até o presente momento de sua formação, não havia tido oportunidade de trabalhar com tecnologias ou jogos. Quando as crianças manipulavam os tablets mesmo que não fossem os aplicativos que estavam sendo trabalhados, estavam descobrindo matemática, pois, propositadamente, todos os aplicativos salvos nos tablets versavam sobre conteúdos matemáticos e "[...] em interfaces touchscreen a análise deve levar em consideração caminhos de interação e não apenas pontos ou construções isoladas” (BAIRRAL, ASSIS, SILVA, 2015, p. 103).

\section{Algumas possibilidades de toques na formação dos futuros professores de Matemática}

Diante do exposto, mostra-se urgente buscar formar uma geração de professores que ensinem Matemática a partir de modelos pedagógicos atinentes à realidade dos alunos do século XXI, que coexistem na cibercultura, assim como, o uso de aplicativos, programas computacionais, Web, software, devem fazer parte da rotina da formação, pois aprendemos de forma mais significativa quando agimos. No caso desses estagiários destacados no presente artigo, de acordo com seus relatórios, para dois deles a experiência foi profícua. Buscou-se durante os estágios discutir e produzir elementos tanto da Matemática quanto da Didática da Matemática, Ponte (2005), utilizando e explorando as possibilidades que os recursos didáticos, virtual e concreto, a fim de que eles desenvolvam autonomia para buscar outras possibilidades para aprender a ensinar Matemática, já que são usuários dos tablets e smarthfones. Porém pesquisas que trazem dispositivos touchscreen ainda são recentes na Educação Matemática e demandam muitas outras, como lembram Bairral, Assis e Silva (2015), mas é, sem sombra de dúvida, um começo.

\section{Referências}

BAIRRAL, M. Do clique ao touchscreen: novas formas de interação e de aprendizado matemático. Disponível em:

<http://36reuniao.anped.org.br/pdfs_trabalhos_aprovados/gt19_trabalhos_pdfs/gt19_2867_texto.pdf >. Acesso em: 7 out. 2013. , ASSIS, A; SILVA, B.C. Mãos em ação em dispositivos touchscreen na educação

matemática. Seropédica. Rio de Janeiro. Editora da UFRRJ. 2015

BARDIN, L. Análise de Conteúdo. Edições 70. Lisboa. 2009 
BRUNO, A. Educação híbrida: múltiplas possibilidades para a aprendizagem contemporânea. II SEMANA DE EDUCAÇÃO: Educação para além do ambiente escolar - Unifesp, ago. 2013. Anais...

CARVALHO, M. Estágio na licenciatura em Matemática: observações nos anos iniciais.. Petrópolis. Vozes/UFAL. 2012

(2010). Números - Conceitos e atividades para educação infantil e ensino fundamental I. 2. ed. Petrópolis: Vozes.

FIORENTINE, D.; LORENZATO, S.. Investigação em Educação Matemática: percursos teóricos e metodológicos. 2. ed. rev. Campinas: Autores Associados. 2007

GIL, A. C. Métodos e técnicas de pesquisa social. 5. ed. São Paulo: Atlas. 2007

PONTE, J. P. da A formação do professor de Matemática: passado, presente e futuro. In: Em Educação matemática: Caminhos e encruzilhadas, Encontro Internacional em Homenagem a Paulo Abrantes, Faculdade de Ciências da Universidade de Lisboa, 14-15 de Julho de 2005. Disponível em: http://repositorio.ul.pt/bitstream/10451/3169/1/05-Ponte\%20\%28Conf\%20PAbrantes\%29.pdf. Acesso em 15 de março de 2015.

Resolução CNE/CP 2/2015 - Diretrizes Curriculares Nacionais para formação inicial de Professores em Nível Superior e Formação Continuada. Disponível em:

http://portal.mec.gov.br/index.php?option=com_docman\&view=download\&alias=17719-res-cnecp-002-03072015\&category_slug=julho-2015-pdf\&Itemid=30192 Acesso em 14 de novembro de 2015

SHULMAN, Lee S. Those who understand: knowledge growth. Teaching Educational Researcher, v. 15, n. 2, p. 4-14, 1986.

TARDIF. M. Saberes Docentes e Formação Profissional. Petrópolis: Vozes. 2002

Submetido em outubro de 2015

Aprovado em dezembro de 2015 